\title{
DEVELOPMENT AND VALIDATION OF AN UV SPECTROPHOTOMETRIC METHOD FOR THE DETERMINATION OF ALISKIREN IN TABLETS
}

\author{
Micheli Wrasse-Sangoi*, Leonardo Trevisan Secretti, Isabel Fração Diefenbach e Clarice Madalena Bueno Rolim \\ Departamento de Farmácia Industrial, Universidade Federal de Santa Maria, 97105-900 Santa Maria - RS, Brasil \\ Maximiliano da Silva Sangoi \\ Faculdade de Farmácia, Universidade Federal do Rio Grande do Sul, Av. Ipiranga, 2752, 90610-000 Porto Alegre - RS, Brasil
}

Recebido em 5/11/09; aceito em 11/2/10; publicado na web em 21/5/10

\begin{abstract}
For determination of aliskiren in commercial samples, an analytical UV spectrophotometric method was developed and validate according to ICH guideline. The method was linear in the range between 40 and $100 \mu \mathrm{gL}^{-1}\left(r^{2}=0.9997, n=7\right)$ and exhibited suitable specificity, accuracy, precision, and robustness. It is simple, it has low cost, and it has low use polluting reagents. Therefore, the proposed method was successfully applied for the assay and dissolution studies of aliskiren in tablet dosage forms, and the results were compared to a validated RP-LC method, showing non-significant difference $(P>0.05)$.
\end{abstract}

Keywords: aliskiren; pharmaceutical formulation; UV spectrophotometry.

\section{INTRODUCTION}

Hypertension is a common chronic disease that leads to significant cardiovascular morbidity and mortality worldwide. Blood pressure control is important for the management or prevention of cardiovascular diseases and their complications. ${ }^{1}$ New antihypertensive agents with a different mechanism of action may play an important role in the optimal management of hypertension. The key factor in the development of any new antihypertensive agent is its potential to effectively control blood pressure. ${ }^{2}$

Aliskiren, (2(S),4(S),5(S),7(S)- $N$ - (2-carbamoyl-2-methylpropyl)5-amino-4-hydroxy-2,7-diisopropyl-8-[4-methoxy-3-(3-methoxypropoxy)phenyl]-octanamide hemifumarate) (Figure 1), the first oral direct renin inhibitor approved for clinical use, exhibits a novel and advantageous pharmacokinetic and pharmacodynamic profile for the long-term treatment of hypertension. Aliskiren blocks the renin system at its rate-limiting step by directly inhibiting the catalytic activity of renin, thereby reducing generation of angiotensin I and angiotensin II..$^{3,4}$

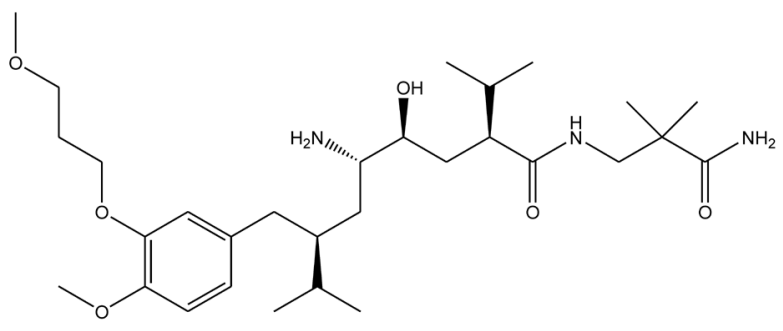

Figure 1. Chemical structure of aliskiren (free base)

The UV-Vis method is very useful in quality control of pharmaceutical products due to the potential of the great majority of the drugs to absorb energy in these wavelengths. The absorption of UVvisible radiation occurs through the excitation of electrons within the molecular structure to a higher energy state. Although the selectivity depends on the chromophore of the drug, the method presents a series of applications: quantification of drugs in formulations where there is

\footnotetext{
*e-mail: micheliw@yahoo.com.br
}

no interference from excipients, pKa determination, release of drugs from formulations with time in dissolution testing, monitoring of the reaction kinetics of drug degradation, and identification of drugs starting from UV spectrum. ${ }^{5,6}$

Recently, a stability-indicating reversed-phase liquid chromatographic method (RP-LC) method was developed and validated for the determination of aliskiren in tablet dosage forms, using acetonitrile and phosphoric acid solution as mobile phase. ${ }^{7}$ In order to obtain a simpler, cheaper, faster, and less environmental toxic method for the determination of aliskiren in tablet dosage forms, an UV spectrophotometric method was fully validated in this study, employing mainly distilled water, as solvent. The validation procedure was carried out according to the International Conference on Harmonization (ICH) guideline by determination of the following parameters: specificity, linearity, range, precision, accuracy, and robustness. ${ }^{8}$ The validated UV method was applied to quantitative analysis of aliskiren in tablets and in vitro dissolution studies, comparing the results with the RPLC method; ${ }^{7}$ moreover contribute to establish new alternatives with advantages for the quality control of the pharmaceutical formulations and assuring the therapeutic efficacy.

\section{EXPERIMENTAL}

\section{Chemicals and reagents}

Aliskiren was extracted from commercial tablets (Rasilez ${ }^{\mathrm{TM}} 300$ $\mathrm{mg}$ ) with ultrapurified water ( $\mathrm{pH}$ 7.0), filtered and then submitted to a SpeedVac concentrator (Model SPD 1010, Thermo Electron Corporation, Milford, MA, USA) until dryness. The obtained powder was analyzed for purity by the proposed method, RP-LC and by liquid chromatography-mass spectrometry (LC-MS) methods. To confirm the identity, additional techniques such as diffuse reflectance infrared Fourier transform spectroscopy (DRIFT) and nuclear magnetic resonance (NMR) were carried out (data not shown). Nonaqueous titration of weak bases was also performed to determine the degree of purity of the drug according to US Pharmacopeia (USP 32). ${ }^{9}$ A total of six batches of Rasilez ${ }^{\mathrm{TM}}$ (Novartis, São Paulo, SP, Brazil) tablets, containing 150 and $300 \mathrm{mg}$ of aliskiren were obtained from commercial sources within their shelf-life period. For all of the analyses, the reagents and solvents used were analytical grade. Ultrapure water 
was used (Labconco, Kansas City, MO, USA). Aliskiren dosage form was labeled to contain the following excipients: magnesiun stearate, macrogol, crospovidone, povidone, microcrystalline cellulose, talc, hypromellose, anhydrous colloidal silica, E171 titanium dioxide, E172 red iron oxide, E172 black iron oxide.

\section{Preparation of aliskiren reference solutions}

\section{UV method}

The stock solution of aliskiren reference substance was prepared by weighing accurately, $11.23 \mathrm{mg}$ of aliskiren hemifumarate $(98.32 \%)$, transferred to $10 \mathrm{~mL}$ volumetric flask and diluted to volume with methanol, obtaining a concentration of $1 \mathrm{mg} \mathrm{mL}^{-1}$ of aliskiren base. Three hundred and fifty microliters of stock solution was transferred to $5 \mathrm{~mL}$ volumetric flask and diluted to volume with water in order to obtain the work solution at concentration of $70 \mu \mathrm{g} \mathrm{mL} \mathrm{m}^{-1}$.

\section{RP-LC method}

The stock solution of aliskiren reference substance at concentration of $1 \mathrm{mg} \mathrm{mL}^{-1}$ (in methanol) of aliskiren base was prepared. The stock solution was stored at $2-8{ }^{\circ} \mathrm{C}$, protected from light and daily diluted to an appropriate concentration in water.

\section{Preparation of sample solutions}

\section{UV method}

To prepare the sample solutions, twenty tablets containing 150 and $300 \mathrm{mg}$ of aliskiren were accurately weighed and crushed to a fine powder to obtain the average weight, respectively. Amounts of powdered tablets equivalent to $100 \mathrm{mg}$ of aliskiren was transferred to a $100 \mathrm{~mL}$ volumetric flask. After addition of $70 \mathrm{~mL}$ water, the flasks were shaken ultrasonically $(5 \mathrm{~min})$. The samples were made up to volume with water and centrifuged $(10 \mathrm{~min}$ ). Aliquots (equivalent to $350 \mu \mathrm{g}$ ) of the clear supernatant liquid were transferred to $5 \mathrm{~mL}$ volumetric flasks and diluted with water to give a final concentration of $70 \mu \mathrm{g} \mathrm{mL} \mathrm{m}^{-1}$.

\section{$R P$-LC method}

An appropriated amount of powdered tablets was transferred into an individual $50 \mathrm{~mL}$ volumetric flask and diluted to volume with water. Then the mixture was vortex mixed for $1 \mathrm{~min}$ and centrifuged for $10 \mathrm{~min}$. The final concentration of $100 \mu \mathrm{g} \mathrm{mL}^{-1}$ of the aliskiren was stored at $2-8{ }^{\circ} \mathrm{C}$, protected from light, daily filtered through a $0.45 \mu \mathrm{m}$ membrane filter (Millipore, Bedford, MA, USA), injected and the amount of the drug calculated against the reference solution.

\section{Methods}

\section{UV spectrophotometry analysis}

A double-beam Shimadzu UV-Vis spectrophotometer (Kyoto, Japan) model UV 1601 PC, with a fixed slit width (2 nm) using $1.0 \mathrm{~cm}$ quartz cells was used for all absorbance measurements. The absorbance was measured at $279 \mathrm{~nm}$.

\section{$R P-L C$ analysis}

The RP-LC method was performed on a LC system (Shimadzu) equipped with an SCL-10A $\mathrm{AP}_{\mathrm{p}}$ system controller, a LC-10 $\mathrm{AD}_{\mathrm{vP}}$ pump, a DGU-14A degasser, a SIL-10AD ${ }_{\mathrm{VP}}$ autosampler, and an SPD-M10A photodiode array (PDA) detector. ${ }^{7}$ The peak areas were integrated automatically by computer using a Shimadzu Class VP (v 6.14) software program. The experiments were performed on a reversed phase Waters (Milford, MA, USA) XBridge $\mathrm{C}_{18}$ column $(150 \times 4.6$ $\mathrm{mm}$ i.d., with a particle size of $5 \mu \mathrm{m})$. A security guard holder was used to protect the analytical column. The Shimadzu LC system was operated isocratically at ambient controlled temperature $\left(25^{\circ} \mathrm{C}\right)$ using a mobile phase of acetonitrile:water (95:5, v/v)/phosphoric acid (25 $\mathrm{mmol} \mathrm{L}-1, \mathrm{pH} 3)(40: 60, \mathrm{v} / \mathrm{v})$, run at a flow rate of $1.0 \mathrm{~mL} \mathrm{~min}^{-1}$, and using PDA detection at $229 \mathrm{~nm}$. The injection volume was $30 \mu \mathrm{L}$.

\section{UV spectrophotometric method validation}

Analytical method development and validation play a major role in the discovery, development, and manufacture of pharmaceuticals. ${ }^{10}$ The UV spectrophotometric method was validated using samples of tablet dosage forms with the label claim of $300 \mathrm{mg}$ by determination of the following parameters: specificity, linearity, precision, accuracy, limit of detection (LoD), limit of quantitation (LoQ), and robustness following the ICH guideline. ${ }^{8}$

\section{Specificity}

Specificity was evaluated by analyzing solutions containing all the components of the aliskiren tablets, excepting the drug. In house mixture of the excipients was prepared in according to the Handbook of Pharmaceutical Excipients. ${ }^{11}$ The system response was examined for the presence of interference or overlaps with aliskiren responses at $279 \mathrm{~nm}$.

\section{Linearity}

The analytical curves were obtained with 7 concentrations of reference solution in the range of $40-100 \mu \mathrm{g} \mathrm{mL}^{-1}(40,50,60,70$, 80,90 , and $\left.100 \mu \mathrm{g} \mathrm{mL}^{-1}\right)$. Each solution was prepared in triplicate. The linearity was evaluated by linear regression analysis by the leastsquare regression method, which was used to calculate the correlation coefficient, y-intercept and slope of the regression line. The curves were validated by means of the analysis of variance (ANOVA).

\section{Precision}

The precision was determined by repeatability (intra-day) and intermediate precision (inter-day). Repeatability was evaluated assaying 6 determinations at the same concentration $\left(70 \mu \mathrm{g} \mathrm{mL} \mathrm{L}^{-1}\right)$, during the same day, under the same experimental conditions. Intermediate precision was analyzed comparing the assays in 3 determinations at the same concentration ( $\left.70 \mu \mathrm{g} \mathrm{mL}^{-1}\right)$ during 3 different days. Precision (repeatability and intermediate precision) was expressed as relative standard deviation (RSD).

\section{Accuracy}

The accuracy was evaluated applying the proposed method to the analysis of the in house mixture of the excipients with known amounts of the drug, to obtain solutions at concentrations of 56, 70, and $84 \mu \mathrm{g} \mathrm{mL}^{-1}$, equivalent to 80,100 , and $120 \%$ of the nominal analytical concentration, respectively. The accuracy was calculated as the percentage of the drug recovered from the formulation matrix.

\section{$L o D$ and $L o Q$}

LoD/LoQ parameters are not a requirement for drug assay; however, it is always useful to demonstrate that the analyses are being conducted in a region which is above the LoQ value. The LoD and LoQ were calculated based on the standard deviation of the response (y-intercepts of regression lines) and the slope using three independent analytical curves, as defined by ICH. LoD and LoQ were calculated as 3.3 and $10 \sigma / \mathrm{S}$, respectively, where $\sigma$ is the standard deviation of the response and $\mathrm{S}$ is the slope of the calibration curve.

\section{Robustness and stability}

Robustness of the proposed method was determined by the analysis of samples and standard solutions $\left(70 \mu \mathrm{g} \mathrm{mL}^{-1}\right)$ at different waveleng- 
ths $( \pm 5 \mathrm{~nm})$, at different solution temperatures $\left(4\right.$ and $\left.25^{\circ} \mathrm{C}\right)$, and at different solution compositions (water; methanol; $0.1 \mathrm{~mol} \mathrm{~L}^{-1} \mathrm{HCl}$ ).

To assess the stability of aliskiren, the stability study was performed maintaining the aliskiren working solution in water for $48 \mathrm{~h}$ at 2-8 ${ }^{\circ} \mathrm{C}$, protected from light, looking for the decrease of absorbance compared with those of freshly prepared solutions.

\section{Tablet properties}

The average weight, friability, hardness, disintegration time, and content uniformity tests of the coated tablets used in the study (Rasilez ${ }^{\mathrm{TM}} 150$ and $300 \mathrm{mg}$ ) were carried out according to Brazilian Pharmacopoeia. ${ }^{12}$ Sample sizes of 20 and 10 tablets were used for determination of weight and hardness, respectively. Friability was determined by using a Pharma Test friabilator (Hainburg, Germany) using 20 tablets for $5 \mathrm{~min}$ (100 revolutions). The disintegration time was determined using 6 tablets in a disintegration apparatus (Nova Ética, São Paulo, Brazil) without discs at $37^{\circ} \mathrm{C}$, in water.

\section{In vitro dissolution studies}

The dissolution rate studies of aliskiren from tablets were performed on a paddle-stirrer type of apparatus by a Nova Ética dissolution test system (São Paulo, Brazil). Drug release tests were carried out according to conventional dissolution procedures recommended for single-entity products in $900 \mathrm{~mL}$ of different media of $0.1 \mathrm{~mol} \mathrm{~L}^{-1}$ $\mathrm{HCl}$ (50 and $75 \mathrm{rpm}$ ), phosphate solution $\mathrm{pH} 4.5$ (50 and $75 \mathrm{rpm}$ ), phosphate solution $\mathrm{pH} 6.8$ (50 and $75 \mathrm{rpm})$, and distilled water (50 and $75 \mathrm{rpm}$ ), for $45 \mathrm{~min} .{ }^{13,14}$ The temperature of the cell was maintained at $37 \pm 0.5^{\circ} \mathrm{C}$ by using a thermostatic bath. At each sample time interval, an exact volume of the sample was withdrawn from each flask and immediately replaced with an identical volume of fresh medium to maintain a dissolution sink condition. A correction factor was included in the calculations to account for the drug lost in the sampling. At predetermined time intervals $(0,5,10,15,20$, 30 , and $45 \mathrm{~min}$ ) for the development of the methodology and for the dissolution studies, the concentrations of aliskiren in the dissolution medium were determined by the proposed UV spectrophotometric method, that were diluted in according to the linearity of analytical method. The cumulative percentage of drug released was plotted against time, in order to obtain the release profile and to calculate the in vitro dissolution data $(n=12)$ by the linear regression equation. ${ }^{12}$

\section{Analysis of aliskiren in pharmaceutical formulations}

For the quantitation of aliskiren in the tablet dosage forms, the respective stock solutions were diluted to appropriate concentration, filtered, analyzed in triplicate and the percentage recoveries of the drug calculated against the reference substance for UV spectrophotometric and RP-LC methods, respectively.

\section{RESULTS AND DISCUSSION}

\section{UV spectrophotometric method validation}

Due to the high solubility of the drug in water, this was chosen as diluting solution. Initially, an UV spectroscopic scanning run allowed selecting the wavelength of $279 \mathrm{~nm}$ as the best for the detection of aliskiren in the reference solution as well as in sample solutions (Figure 2).

\section{Specificity}

In order to verify the absence of interferences of the excipients on the analysis of aliskiren in tablets, we carried out the analysis of

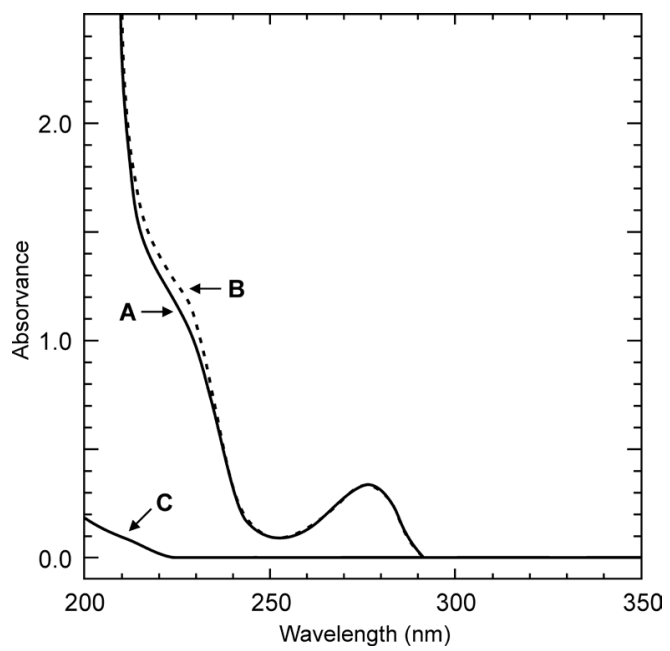

Figure 2. UV spectra of aliskiren solutions in distilled water: (A) reference substance, $(B)$ tablet dosage form and $(C)$ in house mixture of the excipients

a sample prepared with all the excipients present in the tablets, but without the drug (in house mixture of the excipients). Absorption spectra did not show any potential interference of the tablet excipients at $279 \mathrm{~nm}$, also shown in Figure 2.

\section{Linearity}

A linear relationship was found between the absorbance and the concentration of aliskiren in the range of 40 to $100 \mu \mathrm{g} \mathrm{mL} \mathrm{m}^{-1}$. The correlation coefficient was 0.9997 indicating excellent linearity $\left(r^{2}>0.999\right)$. The representative linear equation was $\mathrm{y}=0.0045 \mathrm{x}+$ 0.0163 , calculated by the least squares method. The analytical data were validate by means of ANOVA that demonstrated significant linear regression $(f$ calculated $=1172.64>f$ critical $=4.6 ; P=5 \%)$ and no significant deviation from linearity $(f$ calculated $=0.63<f$ critical $=2.96 ; P=5 \%)$.

\section{Precision and accuracy}

The intra-day and inter-day relative standard deviation (RSD) values obtained by the proposed method were found to be lower than $2.0 \%$. The accuracy of the method expressed as recovery (\%) was between 101.55 and $101.88 \%$. Results are given in Tables 1 and 2, respectively.

Table 1. Intra-day and inter-day precision data of UV spectrophotometric method for aliskiren in tablet dosage form

\begin{tabular}{lccc}
\hline Precision & $\begin{array}{c}\text { Experimental concentration } \\
\left(\mu \mathrm{g} \mathrm{mL}^{-1}\right)\end{array}$ & $\begin{array}{c}\text { Recovery } \\
(\%)\end{array}$ & $\begin{array}{c}\mathrm{RSD}^{\mathrm{a}} \\
(\%)\end{array}$ \\
\hline Intra-day $(n=6)$ & 72.49 & 103.56 & 0.91 \\
Inter-day & & & \\
Day 1 $(n=3)$ & 73.90 & 105.57 & 0.74 \\
Day 2 $(n=3)$ & 74.11 & 105.87 & 0.90 \\
Day 3 $(n=3)$ & 72.52 & 103.60 & 0.81 \\
Mean $(n=9)$ & 73.51 & 105.01 & 1.23 \\
\hline
\end{tabular}

${ }^{\mathrm{a}} \mathrm{RSD}=$ Relative standard deviation.

\section{LoD and $L o Q$}

The values calculated for LoD and LoQ were 2.55 and $8.49 \mu \mathrm{g}$ $\mathrm{mL}^{-1}$, respectively.

\section{Robustness and stability}

The reliability of the proposed method was also evaluated by means of the robustness test. The selected variables evaluated in 
Table 2. Results from accuracy of the UV spectrophotometric method for aliskiren

\begin{tabular}{lccc}
\hline $\begin{array}{l}\text { Nominal concentration } \\
\left(\mu \mathrm{g} \mathrm{mL} \mathrm{mL}^{-1}\right)\end{array}$ & $\begin{array}{c}\text { Mean concentration found } \\
\left(\mu \mathrm{g} \mathrm{mL}^{-1}\right)\end{array}$ & $\begin{array}{c}\mathrm{RSD}^{\mathrm{b}} \\
(\%)\end{array}$ & $\begin{array}{c}\text { Accuracy } \\
(\%)\end{array}$ \\
\hline 56 & 56.87 & 0.21 & 101.55 \\
70 & 71.26 & 0.88 & 101.80 \\
84 & 85.58 & 0.99 & 101.88 \\
Mean recovery $(\%)$ & & & 101.74 \\
\hline
\end{tabular}

${ }^{\mathrm{a}}$ Mean of three replicates. ${ }^{\mathrm{b}} \mathrm{RSD}=$ Relative standard deviation.

the robustness testing are given in Table 3. No significant difference could be observed in the results found out, thus demonstrating that the method was robust. Moreover, the stability of the analytical solution was analyzed and it was found to be stable up to $48 \mathrm{~h}$, showing non-significant change $(<2 \%)$ relative to freshly prepared samples.

Table 3. Conditions investigated during robustness test

\begin{tabular}{lcccc}
\hline \multicolumn{5}{c}{ Absorbance } \\
Variable & $\begin{array}{c}\text { Conditions } \\
\text { investigated }\end{array}$ & $\begin{array}{c}\text { Reference solution } \\
\left(70 \mu \mathrm{mL}^{-1}\right)\end{array}$ & $\begin{array}{c}\text { Sample solution } \\
\left(70 \mu \mathrm{mL}^{-1}\right)\end{array}$ & $\begin{array}{c}\text { Drug } \\
\text { content } \\
(\%)\end{array}$ \\
\hline $\begin{array}{l}\text { Wavelength } \\
(\mathrm{nm})\end{array}$ & 274 & 0.351 & 0.358 & 101.99 \\
& 279 & 0.307 & 0.312 & 101.63 \\
Solution & 284 & 0.312 & 0.314 & 100.64 \\
temperature & 4 & 0.310 & 0.311 & 100.32 \\
$\begin{array}{l}\left.{ }^{\circ} \mathrm{C}\right) \\
\text { Solution }\end{array}$ & 25 & 0.311 & 0.313 & 100.64 \\
composition & methanol & 0.336 & 0.311 & 99.04 \\
& 0.1 mol L ${ }^{-1} \mathrm{HCl}$ & 0.309 & 0.333 & 99.11 \\
Solution & $24 \mathrm{~h}$ & $0.312^{\mathrm{b}}$ & 0.312 & 100.97 \\
stability & $48 \mathrm{~h}$ & $0.311^{\mathrm{b}}$ & 0.315 & 100.96 \\
\hline
\end{tabular}

${ }^{\mathrm{a}}$ Mean of 3 replicates. ${ }^{\mathrm{b}}$ Freshly prepared solutions.

\section{Tablet properties}

According to the pharmacopeial requirements, the physicochemical characteristics of the tablets were evaluated. Table 4 shows the data from average weight, hardness, friability, disintegration time, and content uniformity. A good degree of content uniformity was achieved for the tablet formulations prepared, and the percent deviation did not exceed $5 \%$, indicating excellent content uniformity. Hardness and friability tests evaluate the resistance of tablets to crushing and to friction, respectively. According to the Brazilian Pharmacopeia, ${ }^{12}$ tablets should have a minimal hardness of $30 \mathrm{~N}$ and maximum friability of $1.5 \%$. The tablet formulations fulfilled the compendial requirement for disintegration time for coated tablets $(<30 \mathrm{~min})$. Therefore, the results presented showed that the tablet dosage forms evaluated were in accordance to the official specifications, and these can be suitable for application in dissolution studies.

\section{In vitro dissolution studies}

Dissolution testing is one of the tests most used in the characterization of drugs and in the quality control of dosage forms ${ }^{15}$ It was introduced in the 1960s and has evolved into a test that pharmaceutical manufacturers hope will better predict the in vivo performance of drug products. Dissolution testing is also a requirement for regulatory approval for product marketing and is a vital component of the overall quality control program. ${ }^{16}$

The in vitro studies were performed using 8 different dissolution conditions. According to USP $32,{ }^{9}$ dissolution medium may be water, an aqueous solution (typically $\mathrm{pH} 4.0$ to 8.0 ) or a dilute acid solution ( 0.001 to $0.1 \mathrm{~mol} \mathrm{~L}^{-1} \mathrm{HCl}$ ). Due to the drug is a hydrophilic molecule with high aqueous solubility, ${ }^{17}$ surfactants and electrolytes were not added. As shown in Figure 3 the best dissolution rate profile was achieved with $0.1 \mathrm{~mol} \mathrm{~L}^{-1} \mathrm{HCl}$ as the medium with a paddle rotating at $50 \mathrm{rpm}$. This medium showed better discrimination and is similar to the physiological conditions, and was chosen to carry out the dissolution tests of the batches of aliskiren containing 150 and 300 $\mathrm{mg}$. The concentrations of aliskiren in the dissolution medium were evaluated using the proposed UV spectrophotometric and RP-LC methods giving non-significant difference (data not shown), and the coefficients of variation at the earlier time points, up to $15 \mathrm{~min}$, were within $7.93-9.29 \%$ (acceptable $<20 \%$ ) and the other time points within $0.99-6.12 \%$ (acceptable $<10 \%)(n=12) .{ }^{14}$

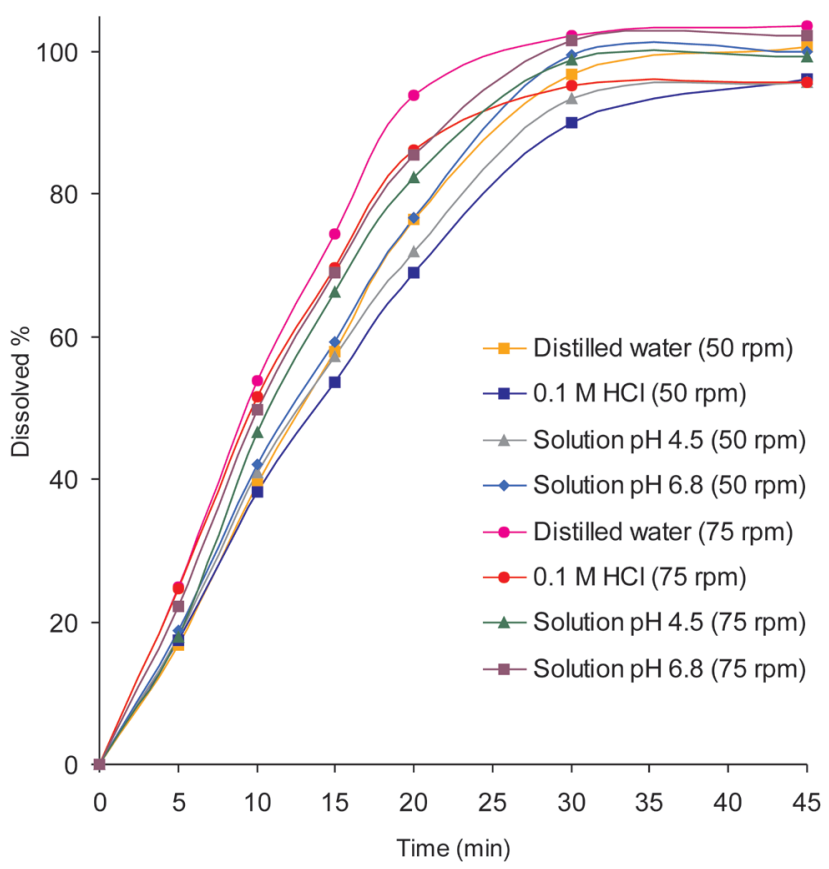

Figure 3. Comparison of dissolution profiles of aliskiren tablets in different dissolution media with paddles (Apparatus 2) using the proposed UV method

Table 4. Quality control tests of commercial aliskiren tablets

\begin{tabular}{|c|c|c|c|c|c|c|c|}
\hline \multirow{2}{*}{$\begin{array}{l}\text { Tablet dosage form } \\
(\mathrm{mg})\end{array}$} & \multirow{2}{*}{$\begin{array}{c}\text { Average weight (mg) } \\
\qquad(n=20) \\
\text { (Weight variation) }\end{array}$} & \multirow{2}{*}{$\begin{array}{l}\text { Friability }(\%) \\
\qquad(n=20)\end{array}$} & \multirow{2}{*}{$\begin{array}{l}\text { Hardness }(\mathrm{N}) \\
\quad(n=10)\end{array}$} & \multirow{2}{*}{$\begin{array}{c}\text { Disintegration time } \\
(\min ) \\
(n=6)\end{array}$} & \multicolumn{3}{|c|}{$\begin{array}{l}\text { Content uniformity }(\%) \\
\qquad(n=10)\end{array}$} \\
\hline & & & & & Lower & Higher & $\operatorname{RSD}(\%)$ \\
\hline 150 & $355.86(346.5-362.4)$ & 0.08 & 121.16 & 13.3 & 96.62 & 97.47 & 0.27 \\
\hline 300 & $710.10(695.0-720.1)$ & 0.08 & 208.31 & 20.0 & 91.94 & 101.14 & 3.33 \\
\hline Limits $^{\mathrm{a}}$ & Average weight $\pm 5 \%$ & Max. $1.5 \%$ & Min. $30 \mathrm{~N}$ & Max. $30 \mathrm{~min}$ & \multicolumn{2}{|c|}{$85-115 \%$} & $\leq 6.00$ \\
\hline
\end{tabular}

${ }^{\mathrm{a}}$ Ref. $12 .{ }^{\mathrm{b}} \mathrm{RSD}=$ Relative standard deviation. 


\section{Comparative determination of aliskiren in commercial samples by the methods}

The validated UV spectrophotometric method was applied for the determination of aliskiren in tablet dosage forms and the results compared to those obtained using the validated RP-LC method giving mean values $0.28 \%$ higher, as shown in Table 5 . The experimental values of the two methods were compared statistically by ANOVA showing non-significant difference $(P>0.05)$. The proposed method can be useful for the determination of aliskiren without prior separation of the excipients of the formulation, with the advantage of low use of polluting reagents and very short analysis time. This simpler analytical technique was employed without losing performance, compared to RP-LC method, which leads to an affordable method and represents an improvement for the quality control of pharmaceuticals.

Table 5. Comparative determination of aliskiren in tablet dosage forms by UV spectrophotometric and RP-LC methods

\begin{tabular}{ccccccccc}
\hline Theoretical amount & \multicolumn{6}{c}{ Experimental amount } \\
\hline Sample & $\begin{array}{c}\text { Dosage form } \\
\end{array}$ & \multicolumn{3}{c}{ UV method } & \multicolumn{3}{c}{ RP-LC method } \\
& $(\mathrm{mg})$ & $(\mathrm{mg})$ & $\%$ & $\begin{array}{c}\mathrm{RSD}^{\mathrm{b}} \\
(\%)\end{array}$ & $(\mathrm{mg})$ & $\%$ & $\begin{array}{c}\mathrm{RSD}^{\mathrm{b}} \\
1\end{array}$ \\
& 150 & 154.32 & 102.88 & 0.26 & 153.31 & 102.21 & 0.15 \\
2 & 150 & 153.09 & 102.06 & 0.27 & 153.26 & 102.17 & 0.21 \\
3 & 300 & 304.53 & 101.51 & 0.27 & 304.05 & 101.35 & 0.24 \\
4 & 300 & 306.72 & 102.24 & 0.41 & 305.34 & 101.78 & 0.29 \\
\hline
\end{tabular}

${ }^{\mathrm{a}}$ Mean of 3 replicates. ${ }^{\mathrm{b}} \mathrm{RSD}=$ Relative standard deviation.

\section{CONCLUSIONS}

The UV spectrophotometric method validated has non-significant difference to RP-LC method and was adequately applied to the quantitative analysis of aliskiren in tablets and in vitro dissolution studies without any interference from the excipients, widely used in routine of quality control laboratories. The UV method is cheap, fast, and produces very low levels of dangerous residues promoting benefits to the public health and the environment.

\section{ACKNOWLEDGMENTS}

The authors wish to thank CNPq for the financial support.

\section{REFERENCES}

1. Lam, S.; Choy, M.; Cardiol. Rev. 2007, 15, 316.

2. Schmieder, R. E.; J. Renin Angiotensin Aldosterone Syst. 2006, 7, S16.

3. Daugherty, K. K.; Am. J. Health-Syst. Pharm. 2008, 65, 1323.

4. Vaidyanathan, S.; Jarugula, V.; Dieterich, H. A.; Howard, D.; Dole, W. P.; Clin. Pharmacokinet. 2008, 47, 515.

5. Paim, C. S.; Gonçalves, H.; Lange, A.; Miron, D.; Steppe, M.; Anal. Lett. 2008, 41, 571 .

6. Watson, G. D.; Pharmaceutical Analysis: A Textbook for Pharmacy Students and Pharmaceutical Chemists, $2^{\text {nd }}$ ed.; Churchill Livingstone: London, 2005, p. 97-116.

7. Wrasse-Sangoi, M.; Sangoi, M. S.; Oliveira, P. R.; Secretti, L. T.; Rolim, C. M. B.; J. Chromatogr. Sci., in press.

8. International Conference on Harmonisation (ICH) of Technical Requirements for Registration of Pharmaceuticals for Human Use; Validation of Analytical Procedures: Text and Methodology Q2(R1), Geneva, November, 2005, p. 1-13.

9. USP 32, The United States Pharmacopeia/The National Formulary, $32^{\text {th }}$ ed.; United States Pharmacopeial Convention: Rockville, 2009.

10. Shabir, G. A.; Lough, W. J.; Arain, S. A.; Bradshaw, T. K.; J. Liq. Chromatrog. Rel. Technol. 2007, 30, 311.

11. Rowe, R. C.; Sheskey, P. J.; Owen, S. C., eds.; Handbook of Pharmaceutical Excipients, $5^{\text {th }}$ ed., Pharmaceutical Press: Grayslake, 2006.

12. Farmacopéia Brasileira, $4^{\mathrm{a}}$ ed., Atheneu, São Paulo, 1988.

13. Moore, J. W.; Flanner, H. H.; Pharm. Technol. 1996, $20,64$.

14. FDA; Guidance for Industry: Dissolution testing of immediate release solid oral dosage forms, U.S. Food and Drug Administration: Rockville, 1997.

15. Ford, J. L.; Rajabi-Siahboomi, A. R. In Encyclopedia of Pharmaceutical Technology; Swarbrick, J.; Boylan, J. C., eds.; Marcel Dekker: New York, 2002, p. 717-728.

16. Allen Jr., L. V.; Popovich, N. G.; Ansel, H. C. In Pharmaceutical Dosage Forms and Drug Delivery Systems, $8^{\text {th }}$ ed.; Lippincott Willians \& Wilkins: Philadelphia, 2005, p. 227-259.

17. Luft, F. T.; Weinberger, M. H.; Kidney Int. 2008, 73, 679. 